University of California, Hastings College of the Law UC Hastings Scholarship Repository

Faculty Scholarship

2010

\title{
Do Blind People See Race? Social, Legal, and Theoretical Considerations
}

Osagie K. Obasogie

UC Hastings College of the Law, obasogieo@uchastings.edu

Follow this and additional works at: http://repository.uchastings.edu/faculty_scholarship

\section{Recommended Citation}

Osagie K. Obasogie, Do Blind People See Race? Social, Legal, and Theoretical Considerations, 44 Law \& Soc'y Rev. 585 (2010). Available at: http://repository.uchastings.edu/faculty_scholarship/1358

This Article is brought to you for free and open access by UC Hastings Scholarship Repository. It has been accepted for inclusion in Faculty Scholarship by an authorized administrator of UC Hastings Scholarship Repository. For more information, please contact marcusc@uchastings.edu. 


\title{
Do Blind People See Race? Social, Legal, and Theoretical Considerations
}

\section{Osagie K. Obasogie}

\begin{abstract}
Although the meaning, significance, and definition of race have been debated for centuries, one thread of thought unifies almost all of the many diverging perspectives: a largely unquestioned belief that race is self-evident and visually obvious, defined largely by skin color, facial features, and other visual cues. This suggests that "seeing race" is an experience largely unmediated by broader social forces; we simply know it when we see it. It also suggests that those who cannot see are likely to have a diminished understanding of race. But is this empirically accurate?

I examine these questions by interviewing people who have been totally blind since birth about race and compare their responses to sighted individuals. I not only find that blind people have as significant an understanding of race as anyone else and that they understand race visually, but that this visual understanding of race stems from interpersonal and institutional socializations that profoundly shape their racial perceptions. These findings highlight how race and racial thinking are encoded into individuals through iterative social practices that train people to think a certain way about the world around them. In short, these practices are so strong that even blind people, in a conceptual sense, "see" race. Rather than being self-evident, these interviews draw attention to how race becomes visually salient through constitutive social practices that give rise to visual understandings of racial difference for blind and sighted people alike. This article concludes with a discussion of these findings' significance for understanding the role of race in law and society.
\end{abstract}

ebates over the nature, definition, and meaning of race have been ongoing for centuries (Gossett 1997; Jordan 1968). Until the mid-twentieth century, the dominant perspective was that social categories of race reflect inherent biological differences. This supported a Eurocentric idea that there is a natural racial hierarchy that reflects each groups' innate abilities (Gould 1996). While this perspective has been discredited over the past few decades, bodies and phenotype continue to dominate how we understand race.

The author wishes to express his gratitude to Lauren Edelman, Kristin Luker, Neil Fligstein, Sarah Song, and Ian Haney López for their thoughts and comments throughout this project. A special thank you is also in order to Samuel Lucas, Ann Morning, Dorit Rubinstein Reiss, and Aliya Saperstein for reviewing previous drafts of this article. Please direct all correspondence to Osagie K. Obasogie, University of California, Hastings College of Law, 200 McAllister Street, San Francisco, CA 94102; e-mail: obasogie@uchastings.edu.

Law E Society Review, Volume 44, Number 3/4 (2010)

(C) 2010 Law and Society Association. All rights reserved. 
Indeed, if there has been one constant throughout these shifting and contested understandings, it is the widespread and largely unquestioned belief that race is primarily a matter of visually obvious physical features. ${ }^{1}$ Other factors such as language and culture certainly inform our racial imaginations. Nevertheless, a consistent and dominant feature of race is that it is thought to primarily derive from self-evident and visually obvious human differences.

This emphasis on the visual character of race can be summarized as having at least three components: (1) race is largely known by physical cues that inhere in bodies, such as skin color or facial features; (2) seeing race is an unmediated experience, meaning that these cues are thought to gain their salience from their selfevidently striking nature; and, inferentially, (3) people without vision are thought to have a diminished understanding of race. Through this trope, talking about race outside of visual references to bodily differences seems absurd, lest we all become "color-blind" in the most literal sense. Indeed, part of the rhetorical value in the emerging color blindness discourse is the idea that race and racism are problems of visual recognition, not social or political practices (Siegel 2000).

But how much does the salience of racial categories and race meanings depend upon what is visually perceived? This article challenges existing understandings of race by investigating the significance of race outside of vision. Without dismissing the role of visual cues to race, I empirically investigate the significance and relevance of visual cues in social understandings of race by asking: How do blind people understand race? My hypothesis starts from the somewhat counterintuitive premise that the salience and significance of race depend little on what we see; taking vision as racial truth may very well obscure a deeper understanding of precisely how race is communicated and socialized, as well as how race plays out in everyday life.

I test this hypothesis by interviewing people who have been totally blind since birth about race. It is largely assumed that race has diminished significance for blind people because they cannot observe or respond to the visual cues that have come to define racial difference. But this may not necessarily be the case; race may very well be as significant - even visually significant - for blind people as it is for those who are sighted. Moreover, it is likely that the social, cognitive, and other nonvisual interactions shaping blind

${ }^{1}$ The view of race "still popular today [is] that there exist natural, physical divisions among humans that are hereditary, reflected in morphology, and roughly but correctly captured by terms like Black, White, and Asian" (Haney López 1994:6). Morphology is "the size, shape, and structure of an organism or one of its parts," e.g., visually observable attributes (The American Heritage Science Dictionary, Houghton Mifflin Company, 9 July 2008, http://dictionary.reference. com/browse/morphology $\rangle$ ). 
people's racial experiences and visual understandings of race are not unique to them. A comparative research design that analyzes the racial experiences of blind and sighted people can offer significant insights into how framing race as a visual experience may limit a deeper understanding of the extent to which race shapes everyday life. Contrary to popular belief, race may not simply be a self-evident part of the social world. Rather, there may be social practices that constitute the salience with which we experience these visual distinctions.

It is important to note from the outset what this article is not doing. This research is not an effort to demonstrate the wellestablished concept that race implicates multiple variables such as language, culture, and religion (Omi \& Winant 1994). Nor is it simply another demonstration that race is a social construction, which stands for the idea that the various meanings society places on racialized bodies stem from social forces committed to maintaining racial hierarchy rather than any inherent abilities biologically conferred to each group (Haney López 1996; C. Harris 1992). These are important contributions already made by social constructionists and Critical Race scholars. This article is a secondgeneration effort in this tradition that seeks to question a fundamental aspect of race epistemology - that race is what we see - and to demonstrate empirically the social interactions that create the visual significance given to race. Moreover, this project challenges the widespread belief that vision is necessary to having a full understanding of race. In short, I find that (1) blind people's understanding of race is as significant as their sighted counterparts and that blind people understand race visually, (2) this visual understanding of race stems from social practices that train people to think about race visually regardless of their ability to see, and (3) blind people's visual understanding of race has a significant impact on how they understand themselves and interact with others. Put simply, blind people experience race just like everyone else: visually. How can this be?

To date, research on race in the blind community has largely been limited to discussions on how to deliver services that are culturally competent or understanding how blindness has different effects in various communities (Madeline \& Erin 2001; Stienstra 2002). But there has not been research on how blind people understand and experience race, nor has there been researchempirical or otherwise-examining the social practices that give rise to visual understandings of race. To be sure, while theoretical work in the social sciences has explored the social construction of race-how meaning attaches to bodies-empirical research in the social sciences has largely treated race as a series of preexisting social categories (Martin \& Yeung 2003; Niemonen 1997). (Notable 
exceptions to this trend include Ahmed et al. 2007; Loveman \& Muniz 2007; Penner \& Saperstein 2008; and Telles 2002.) Similarly, legal scholarship has had a robust conversation on how the presumed immutability of race informs various aspects of legal doctrine, but it continues to assume that the intuitive salience of race comes from self-evident visual cues (Braman 1998; Yoshino 1999). To be sure, Law and Society scholarship has also not been as robust as it could be in incorporating constructionist perspectives in its race scholarship, let alone critique the presumption that race is visually obvious (Gómez 2004; Obasogie 2006a). ${ }^{2}$ It is in the context of this existing literature that research on blind people's understanding of race might allow scholars to add a qualitatively different credence to the claim that race is a social construction and, at the same time, move the conversation in new directions by highlighting the social processes outside of vision that constitute racial categories' perceptibility and salience.

In the next section, I provide a theoretical framework for distinguishing between past constructionist approaches to race and the constitutive approach that I propose. Drawing upon art history literature, I discuss how what we see is not an unmediated engagement with the social world but is rather conditioned by social practices that produce the attention one pays to various distinctions. I then discuss this project's research design and methodology concerning my interviews with blind people on their understanding and experiences with race. This then leads to my research findings, which are separated into two parts: (1) a discussion of blind and sighted respondents' visual understanding of race, and (2) a discussion of the visualization of race as a social rather than merely ocular phenomenon - to the point that even blind people, in a sense, "see" race. In the conclusion, I discuss these findings' significance for understanding the role of race in law in society.

\section{Theoretical Framing}

Critical Race Theory has made several important contributions to academic understandings of race, including theories of intersectionality (Crenshaw 1991; Kwon 1997; Obasogie 2006b), anti-essentialism (A. Harris 1990; Wing 1997), and establishing storytelling as critical methodology for illuminating racial injustice

${ }^{2}$ Gómez writes that Law and Society scholars "have not engaged the claims put forward by critical race scholars over the past 15 years or so. And even when they do so, they have not taken the literature as seriously as they might" (Gómez 2004:454). Gómez suggests that this may stem from the fact that Law and Society scholars "conceive of race as a readily measurable, dichotomous (black/white) variable that affects the law at various points ... a concept that is relatively easy to map. But race is complicated, and the relationship between race and law is messy" (Gómez 2004:454). 
(Bell 1993; Williams 1987). Arguably, its most significant contribution has been its repeated demonstration of the social and legal construction of race (Flagg 1993; Haney López 1994; C. Harris 1992). This concept has largely stood for the premise that social and legal forces create the meanings that people attach to different human bodies - a significant departure from decades of discussions in the social and natural sciences that social categories of race reflect inherent biological differences that confer fundamentally different abilities and disabilities to each group. Indeed, as Crenshaw notes, the social constructionist thesis has been instrumental in "challen$\mathrm{g}$ [ing] the ways in which race and racial power are constructed and represented in American legal culture and, more generally, in American society as a whole" (Crenshaw et al. 1995:xii).

While this has significantly improved scholars' understanding of race and set forth a number of challenges, a fruitful direction to move this work is to go beyond the construction of race-descriptive accounts of how social meaning is created, attached to human bodies, and enforced through power structures and relations - to engage a constitutive account that examines how and why societal notions of race have oriented around particular visible differences in skin color and other phenotypic characteristics. The terms construction and constitutive are at times used interchangeably in the literature (McCann 1996). I emphasize the term constitutive in this article to extend yet distinguish constructionist accounts of the macro-social processes that lead meanings to attach to bodies in order to describe a more particular process of the micro-dynamics that give rise to individuals' visual understandings of race. Although McCann does not distinguish between constructionist and constitutive accounts and does not use the terms in the same way as Critical Race Theorists, he usefully notes that

social conventions and knowledges ... [can be] understood as "constitutive" rather than independent, exogenous, discrete determinants.... The term expresses a sensitivity to the ways that our actions are at once delimited and enabled by a complex mix of partial, dialectically interactive knowledge-based (or discursive) factors (McCann 1996: 463).

It is this closer, empirical investigation into social interaction and human consciousness that distinguishes a constitutive approach to race from the constructionist thesis that has focused on broader historical and theoretical trends. Put another way, a constitutive approach to race is less interested in the top-down, seemingly deterministic influences of institutions and historical trends and is more interested in the social practices that make certain approaches to race thinkable, coherent, and commonsensical on an individual level. 
Scholars in the humanities have paid particular attention to what many call the pictorial turn - a moment not unlike previous deconstructive approaches to language - to examine "the constituted rather than the found quality of seemingly natural phenomenon" (Jay \& Brennan 1996:3). The attention these scholars have paid to the constitutive nature of vision has brought great insight into historical and theoretical work concerning identity issues involving race, gender, and sexuality (Geyer-Ryan 1996; Rose 1986). This point regarding the ways in which experience structures visual observation has been most eloquently expressed by a small group of art historians (Berger 2005; Crary 1994, 1999; Johnston 2006; Pinder 2002). Indeed, what Berger's Sight Unseen does for art history, this article attempts to do for law and society: Provide an understanding of how visual observations and their salience are not neutral or unmediated engagements with the world but rather produced, so to speak, from the "inside out" by iterative social practices that make seeing the world a certain way possible-particularly when it comes to race. Berger explains:

Despite the human propensity to privilege sight, and the longstanding Western tendency to root racial designations in observable traits, images do not persuade us to internalize racial values embedded within them, so much as they confirm meanings for which the discourses and structures of our society have predisposed us. Instead of selling us on racial systems we do not already own, the visual field powerfully confirms previously internalized beliefs (Berger 2005:1).

This is an important point that works from constructionist theories concerning the idea that race does not reflect any inherent meanings. But it pushes this thesis to suggest that the very cues that have come to signify racial boundaries may not be as self-evident as widely believed. This focus on how social relations and forces produce visual experiences is a more robust articulation of how particular cues become visually significant. It takes account of the iterative practices that shape a learned behavior without giving primacy to history as a deterministic force-a tendency seen in many constructionist writings.

This sensibility influenced by the aforementioned art history literature is separate yet connected to the constructionist thesis and suggests that important work remains to examine the micromechanics in which social understandings of race have come to orient around particular visible human differences. While some social psychologists have begun looking at how certain stereotypes shape perception (Eberhardt et al. 2004), a more particular understanding of how what we "see" is constituted by broader social practices has largely escaped the scholarly purview of most social scientists as 
well as Critical Race Theorists and legal scholars. This article attempts to develop the constitutive sensibility found in art history to fill this gap within sociolegal research by empirically investigating how visual cues associated with race become salient. This is explored in the next two sections by examining how blind people understand and experience race.

\section{Research Design and Methodology}

Data collection for this project was based on a series of semistructured interviews with sighted and totally blind adults of diverse ages, racial backgrounds, and residences. The interview schedule was the same for both sighted and blind respondents but was designed with enough flexibility to permit follow-up questions as needed in order to have the clearest possible understanding of the interviewees' responses (Gray 2004; Richardon et al. 1965). The interview schedule included questions such as:

How do you define race?

What is your first memory of race?

If you dated or married outside of your race, how did/would your

family respond?

Is knowing someone's race useful to you?

Why do you think some people find race to be important?

In order to have a precise understanding of vision's role for individuals' understandings of race, this research focuses on people who have been totally blind since birth. My preliminary conversations with potential respondents revealed that partially sighted individuals can often see the visual cues associated with race, and individuals who lose their sight later in life often have memories of these visual cues that ultimately shape their understanding of race after becoming blind. As such, it became clear that the best way to understand the relationship between social influences and visual understandings of race is to talk to individuals who have never visually engaged with the cues and body markings that have come to define race. Accordingly, interviews with people who were partially sighted or became blind later in life did not qualify for the study and were excluded. The research design included a small sample of sighted individuals as comparison cases to examine whether or not blind people's understandings of race are different than sighted people's. Interviews with sighted individuals were also used to empirically ground parts of the motivating hypothesis: that sighted people largely define race by visual cues and that they think blindness leads to a diminished understanding of race. 
The vast majority of questions were asked to both sets of respondents. Both blind and sighted respondents were selected through snowball sampling (Weiss 1994). For example, I started with three blind people, interviewed them, and asked each respondent to put me in touch with other blind people. Interviewees were also identified through posting calls for participation on various Internet listservs. Interviews were conducted primarily by telephone, which diversified the sample beyond my immediate geographical limitations and enabled many more blind respondents to participate. Many blind people do not live entirely independent lives; talking by phone was the most accessible means for their participation and provided the least disruption and most comfort.

All empirical research has biases and limitations (Hammersley \& Gomm 1997; Weiss 1994). Snowball sampling and using the Internet to identify subjects may raise some concerns about selection bias. These methods run the risk of yielding the same type of respondents over and over again. However, snowball sampling is routinely used in qualitative research, especially when the targeted group - such as individuals who have been totally blind since birth - is difficult to access (Faugier 1997). Using the Internet to recruit respondents might lead some to question whether this approach is biased toward younger and wealthier adults or professionals who are more accustomed to online communication and have greater access to it. However, the respondents' demographics suggest that this may not be the case; they were individuals of diverse ages, economic means, educational backgrounds, geographic regions, and political persuasions.

Interviewer bias is also a common concern with qualitative research (Groves et al. 2004). In particular, an interviewer's race may affect an interviewee's response when the research topic is on racial attitudes and perceptions (Davis 1997). This concern usually comes out of cross-racial interviews where a person of one race observes that he or she is being interviewed by a person of another race and adjusts his or her answers accordingly. Given that the interviews were conducted by telephone, the observational effects of any cross-racial difference did not play a role, although other racialized cues such as voice, accent, or surname may have had a subtle effect (Lippi-Green 1997).

Over a three-month period, I conducted 110 interviews with blind respondents, with 59 individuals qualifying as being totally blind since birth. I tried to balance the respondents' ages in the two groups (blind respondents had an average age of 45.4 years while sighted respondents had an average age of 52.1 years) so that the experiences would be comparable. I also tried to balance the proportions of white and nonwhite blind respondents (69 percent of 
the blind respondents identified as white and 31 percent identified as nonwhite, compared to 67 percent of the sighted respondents identifying as white and 33 percent identifying as nonwhite). There were significant gender differences between the number of blind and sighted respondents. However, there is no evidence that this imbalance adversely affected the results (see Table 1 ).

Each telephone interview was recorded with the respondents' consent, transcribed by a third party, and imported into HyperResearch qualitative research software for coding. A codebook was developed, whereby a number of codes were used to parse and find commonalities between the interview data. Codes were developed in two ways. First, there were concepts that I specifically wanted to identify, such as the frequency with which interviewees used visual cues to describe race. Examples of these codes included "race as skin color or visual cue" or "race as biology." Other codes were developed after the interviews were complete but before coding. During the interviews, several concepts that I did not anticipate emerged, such as blind white respondents saying that they know what it is like to be a racial minority because of the discrimination they experienced as blind people. Other unexpectedly recurring themes included the role of smell in blind people's race socialization and blind people's experiences with attending racially segregated schools for the blind. These recurring themes were tracked and coded.

\section{Results}

The results of the research are organized around two specific inquiries: first, to what extent do blind people "visualize" race, and second, to what extent is the visualization of race a social phenomenon?

\section{Visualizing Race in Sighted and Blind Communities}

\section{Visual Cues and Sighted Respondents}

Before examining blind people's understanding of race, it is useful to explore the extent to which race is conceived of visually within the sighted community. Each of the sighted respondents defined race through visual cues. For example, when asked if there is anything that she associates with race, Sally ${ }^{3}$ said "the physical basis, basically skin color or [other] characteristics." Mary corroborated this sentiment by noting, "Race is the color of a person's skin," as did Terry, who noted that race reflects "differences that are very obvious, such as skin color, eye color, hair color." Sighted

\footnotetext{
${ }^{3}$ Pseudonyms are used throughout this article to protect respondents' identities.
} 


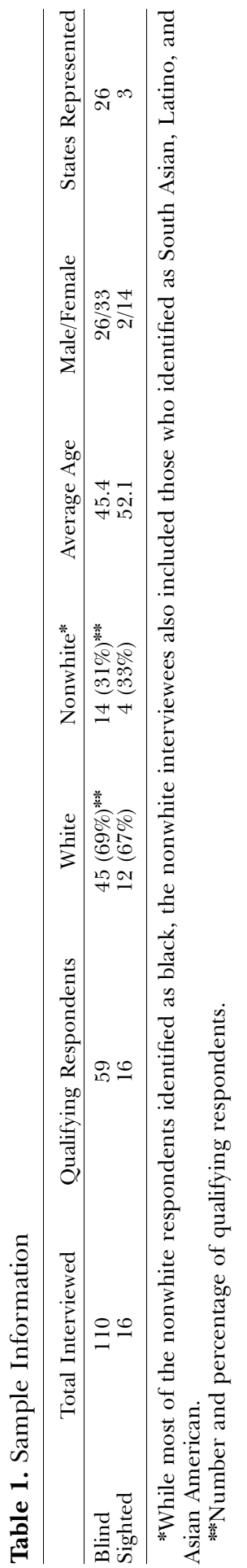


respondents certainly had a subtle understanding of the way race concepts interact with and are influenced by other identity characteristics such as ethnicity, nationality, and language (Waters 1990). Nevertheless, there was a resilience with which visual cues defined race; the aforementioned subtleties quickly became insignificant to respondents' primary identification of race with visual cues.

This visual understanding of race among sighted respondents that focuses on phenotype and other seemingly obvious distinctions mirrors the self-evident nature by which race is discussed in sociological and legal literature (Gómez 2004; Martin \& Yeung 2003; Niemonen 1997). Yet this visual understanding of race also influences how sighted people think blind people understand and experience race. Most of the sighted respondents thought that blind people's understanding of race and its importance to their daily lives were diminished by not being able to see. When asked whether she thought race is an issue for blind people, Tammy said, "No, I don't. I guess, because I identify race by physical characteristics." Jimmy felt the same way, saying that race is not "as big an issue as it is for people who can see." When asked whether she thought blind people understood race, Marcy wishfully said, "Oh I hope not! Wouldn't that be wonderful if nobody knew!"

Some sighted respondents thought that blind people might have a limited sense of race that does not find visual markers meaningful but draws distinctions based on voice and accent. For example, Terry thought that race can still matter to blind people "because people sound different, and people act differently," while David thought that even though blind people cannot see physical differences, there are "cultural difference that can be identified more so than the pure color." While these responses demonstrate a subtlety toward race, they nonetheless reassert the central understanding of race as "pure color" that can only be significant to blind people by proxy: language, behavior, food, and other racialized characteristics linked to senses other than sight.

Taken together, the sighted respondents in the sample appeared to believe that race has a diminished significance for blind people because they cannot detect its visual cues. Those respondents who thought it might be important to blind individuals largely limited this significance to ancillary aspects of race such as detecting racialized voices or smelling racialized foods. But for the most part, they maintained that blind people have little appreciation for the primary significance of race: visible physical differences.

\section{How Do Blind People Understand Race?}

Put simply, blind people largely understand and experience race the same way that sighted individuals do: visually. The vast 
majority of blind respondents in this study primarily associated race with skin color and other visual traits. This visual association went beyond a general awareness of how sighted individuals approach race. Rather, it profoundly shaped the way blind respondents thought about and experienced race. It also affected their response to race at deeply emotional levels; it is not uncommon for blind people to organize their life activities around the notion that groups have striking visual differences.

When asked about the first thing that came to mind when hearing the word race, Betsy, a blind woman, said, "It's a way of dividing up human beings according to the color of skin." Most blind respondents answered this way, such as Daniel, who noted that "race [is] skin color - color of one's pigmentation," or Perry, who said that race is "primarily skin color." Danielle, for example, said that race led her to think of "different colors of people like blacks, Indians, Asians." What quickly emerged from these interviews was that blind people reported thinking about race in terms of skin color and other visual attributes. They often emphasized skin color and other visual cues in a matter-of-fact tone, such as Aliya, who noted in a deadpan tone that race reflects "physical attributes that are inherently unique to a group of people" and Tony, who quipped that race "is color. Even though I can't see, that's what I tend to think of."

This visual understanding of race often went beyond mere skin color to demonstrate a rather sophisticated understanding of the range of visual cues that can make one race different from another. Ronald explained that race reflects a collection of "physical attributes that make people different from each other [such as] skin color, maybe type of hair, maybe [other] physical features." Laurel went a bit further, noting that race

is not only skin color because it's also [other] characteristics. ... Various races like the Negroid race have the characteristic of [different] bone structure [and] facial structure. Asians [also] have [different] facial structure [and] body structure. I know that each race has its own set of characteristics to go with it. Color can be a defining characteristic. But [race] is not only based on color.

Another blind white respondent, Jens, talked assertively about the relationship between race and visual cues, noting that "white is pretty generic to me.... Most black people look pretty much the same with a few exceptions. Of course it always depends on the person, but in general, they look pretty much the same I think." This statement is interesting to the extent that it demonstrates a belief that the visual cues tied to race are more diverse within his own racial group. This parallels research on cross-racial identification in the sighted community, where members of one racial 
group are more capable of remembering distinguishing facial characteristics of members of their own group than members of other racial groups (Bothwell et al. 1989; Meissner \& Brigham 2001). Taken together, this discussion of primary and secondary visual cues linked to racial categories - as well as these characteristics' distinctiveness within and among racial groups-highlights the subtle ways in which blind people engage race's visual components.

These statements begin to demonstrate a theme that is repeated throughout this article: The significance that society attributes to visual aspects of race comes less from any obvious or self-evident physical differences and more from how social practices train individuals to look differently on certain bodies. This is a subtle point that becomes clearer as the data present themselves. But what has emerged thus far is that in general, both blind and sighted people understand race in visual terms, suggesting that there is a significant shared social experience that not only gives race its meaning but makes it perceptible in the first place. This leads to the project's key finding: The very presumption that race is visually self-evident is part of a constitutive social process that produces a visual understanding of race at the same time that it masks its own existence by making race seem obvious. Dennis, a blind respondent, provided a bit more insight:

I think a lot of what people don't understand is that blindnessthe simple lack of sight - is not a very important factor in these things. ... [Blind people] are exposed to the same kinds of influences anybody else has, and it's not unusual to find that blind people are the same as their sighted peers, in regard to any of these issues, and the only thing that draws attention to the blindness is the fact that in America, the race issue is so identified with color. I know blind people who, before they decide how they're going to treat somebody, are going to find out, "Is this person a black person, or is he a white person?"

If blind people understand race in the same visual manner as their sighted counterparts, how is it that something such as skin color-a concept whose coherency is inextricably tied to vision-becomes meaningful to people who cannot see? What does skin color mean to a blind person, and how does it affect interactions with other groups?

These data, along with research on how blind people understand color, suggest that phenotype and other visual cues become shorthand for difference and contrasts (Connolly et al. 2007; Marmor 1978). With regard to blind people's understanding of race, these categories of difference need not take on a positive character that can be directly perceived; difference as a label 
signifying something unlike the self is enough to fill those categories with a sentient value that then becomes known as "race" for both blind and sighted people.

These interviews highlight the extent to which cognition of human variation based on visual cues can, without someone actually being able to see, firmly establish the central creed of racial difference in the minds of blind individuals. When asked what racial categories such as black and white mean, a blind respondent said:

Black means ... I don't know what that exactly means. But it means they're not White or they're not Asian. ... That's what makes them different races. But I don't know how different they are. From a technical point of view ... their appearance, their skin color, some facial features, and other things that I'm not aware of [separates races]. [There are] physical characteristics that are typical or definitive for one race over another.

From this perspective, racial categories as cognitive labels have very little content to themselves outside of the fact that they are somehow mutually exclusive (e.g., black is known by not being white or Asian) and that this difference is marked by visual attributes that, in turn, might have some type of social meaning attached to them. For example, Saul noted that when the concept of race is mentioned, "usually what I think of is skin color. And a lot of stereotypes that might go along with that [such as] Asian means really smart."

While sighted people often take race to be visually obvious, these examples highlight the extent to which visual understandings of race are much more the result of a social process than is often credited. The attention paid to visual distinctions reflects the human capacity to create difference rather than presumably obvious differences having some inherent salience that presents itself to individuals (Hirschfeld 1996; Sampson 1999). As Jeremy eloquently put it, "I don't believe that prejudice is a visual concept. I don't think it's because of what you see that you're racist or that you have strong racial feelings. I think it's more of what you learn and then you use your eyes to identify it. I don't think it's from the physical out. I think it's more inward. I think it's more inside you if that makes any sense." Mickey, also a blind respondent, corroborated this sentiment:

Race is very often not a mystery to blind people. Which is in a sense kind of sad. I think that sometimes [sighted] people look at blind folks and they think well, these people can show us the way to a kind of Star Trek race-blind society. And it would be great if we could do that. But we're just as much a victim of racial prejudice, stereotypes, and misconceptions as anybody else. And the fact 
that we're not clued to it directly by vision doesn't, in my mind, change that a bit. I think that I suffer all of the unfortunate characteristics of my upbringing regarding race that my [sighted] brothers and sisters do.

\section{Blind Respondents' Use of Secondary Characteristics of Race}

Other sensory experiences also affirm the salience of race for blind people without displacing the primacy of its visual significance. Voice is probably the most significant of these experiences. While no sighted respondents identified voice as an important secondary characteristic, more than half of the blind respondents reported using accents, tones, and speech patterns as a way to estimate a person's race. This should not be surprising (LippiGreen 1997). What is surprising, however, is that these audible clues did not stand in for the visual cues a sighted person might rely upon, nor did they become primary in how blind respondents conceived race. Rather, voice and accent remained secondary measures used to give a sense of what is thought to be the primary characteristic of race: visual cues. For example, Tanya stated that voice and accents do not "really mean anything to me, except that I know that they have a different skin color." These findings suggest that differences in voice do not make up the substance of race for blind respondents but rather provide a way to mark a racial difference that is most often understood in visual terms. As Jan noted, voice and accent are useful to the extent that they help her answer the question "What would I see if I looked at you?"

But it is also useful to point out that while most blind respondents reported relying upon voice as a secondary characteristic, other blind respondents distrusted it as a useful proxy for determining race. As Rachel noted, "As I got older, I learned that [voice] is not a good way to identify someone-like using someone's accent or way of speaking to identify them as a particular racebecause it's not reliable." These respondents recalled embarrassing moments where an unknown person's speech patterns led them to assume they were one race, only to find out that this assumption was wrong. Tamara plainly stated that voice is "not a foolproof way of guessing. ... I wouldn't even say it's pretty reliable." Despite these concerns, these respondents continued to use voice as a way to guess a person's race. It is just that they distrust its reliability; it informs without being determinative.

In addition to voice, other senses are also used by blind respondents to perceive what are thought to be primarily visual differences between the races. Several respondents referenced blacks' hair texture as a telltale sign of racial difference (Caldwell 1991). This may reinforce mainstream sentiments in that if such 
distinctions are perceptible through other means, some blind people may conclude that the distinctions must also be visually striking. Brian, a blind white respondent, recalled the first time he touched a black person's head in 4th grade, noting, "It just felt strange compared to my hair because it felt different. The texture was different. I can actually feel it in my mind, right now. ... And I was just like, 'Wow, everything is different about this guy!"' Skin texture also played a notable role. For example, Jens, a blind white man, noted that "I've felt some [black people] and there is kind of a difference in their skin.... Those who are Caucasian or white tend to have a little smoother skin. Black people tend to have rough skin. Or if they're women, they're not exactly as smooth as white women."

Though only mentioned by a handful of blind respondents, probably the most intriguing sense used to detect racial difference was smell. These respondents may have unusually discriminating noses, but they brought up smell as a racially distinguishing factor without any prompting. For example, Carl said,

People from different races to me tend to smell different. Now, usually the way I can identify someone of a different race is that they smell different than a Caucasian person. Hispanic people smell different than black people. And Asians have their own odor. But I'm not as familiar with it because I haven't really been exposed to that many Asians. But I'm sure if I had been that I'd be able to distinguish between the various Asians. But what most comes to mind is Hispanic people smell very different than Caucasian people and black people.

Even amongst the different Hispanics, like the Central American group tends to smell different from Mexicans. But it's a distinct odor. And I don't think it's related to diet either because ... second- and third-generation Hispanics smell more similar to the first-generation ones than white people would. And they're following an American diet. There's one particular case that I distinctly remember when I was in high school. We had this one girl who was blonde and blue-eyed. And she spoke perfect English. And everybody thought that she was Caucasian. And I would say no, she is Mexican obviously. And then it came up in conversation that her father was born in Mexico. And even though she was blonde and blue-eyed, she was half Hispanic. To me she smelled Hispanic. So I knew she was Hispanic even though everybody else thought she was completely Caucasian.

Timothy, another blind respondent, said, "Some black people have an odor about them that you know they cannot help. ... The odor is like a perspiration type thing is what it reminds me of." Margaret recalled one of her first racial experiences in which odor became a 
medium of racial difference, noting, "The first experiences [with race] I had was [with] a girl in my school who was black. ... The thing that I remembered about her, I hate to say this, was that she had a smell about her, an odor about her."

Surely, we all know individuals who emanate unique odors. But to associate particular smells with an entire group of people seems a bit peculiar. This may be an example of how being taught to think racially plays itself out differently for some blind people, who are socialized to draw tight connections between race and nonvisual sensory perceptions to give significance to race as a visual entity. I discuss this process further in the next section. Nevertheless, this example highlights the extent to which race labels and attendant notions of difference can interact with other senses to reconstitute the idea that racial difference is real, concrete, and visually obvious - concepts that are also prevalent within sighted communities. For example, Carl attributed this unique ability to identify races by their smell to "genetically distinct oils that we make in our skin."

As we tie these threads together, what becomes apparent is that the ability to see the markings that typically define racial boundaries is neither necessary nor sufficient in explaining the strong association of race with visual cues. If blind people define and react to race in primarily visual terms, then the empirical evidence begins to poke holes in the assumption that race is visually obvious, self-evident, or an unmediated experience of observing human variation. Something much deeper is at play.

\section{Visualization as a Social Phenomenon}

\section{Social Practices}

In addition to showing the extent to which blind people understand and experience race primarily through visual cues, the interview data also highlight the key role played by social interactions in giving blind respondents a visual sense of race. The blind respondents who articulated a visual understanding of race were likely to link it to early socializations during childhood and adolescence by friends and family members. As a vast amount of social science literature demonstrates, social practices play a significant role in shaping human cognition - particularly how people think about race (Hirschfeld 1996; Kang 2005; Krieger 1995; Sampson 1999). A recurring theme throughout this research is the extent to which friends and relatives went out of their way to not only make sure blind people knew the social importance of race and all the rules, norms, and meanings that go along with it, but also that they thought visually about race so that human physical differences would be experienced as a fundamental lens through which to view the world. 
Yet it is crucial to understand that the practices behind this race socialization are not unique to blind people. Everyone is subject to them. Blind and sighted are part of the same social milieu that directs individuals to pay inordinate attention to visual cues denoting race through which people organize their lives. This process is effortlessly transparent for sighted people, whereby racial knowledge is thought to be visually obvious. But the process takes a bit more work for blind people, who are detached from vision's ability to seduce them into uncritically reducing race to what is seen. Blind people are uniquely capable of discussing the social practices that give the visual cues associated with race an obvious feel. To the extent that blind and sighted people occupy the same social environment, the social forces that give visual understandings of race their coherency to blind people are likely to be similarly influential for those who are sighted. The irony pointed out by this article is that sighted people are, in a sense, blinded by their sight; their vision prevents them from "seeing" or appreciating the social factors that make their visual understandings of race seem obvious, tangible, and coherent.

Tony offered an example of how social practices can lead blind people to think visually about race, noting that skin color defines race for him because "that's what people talked about when I was little and [when] I was first introduced to people of races other than my own. They used terms that had to do with skin color." Visual cues - and their coherency-transmuted through friends and family became part of the respondent's racial lexicon, where characteristics such as skin color and facial features were linguistically prioritized over other aspects of race in early childhood conversations. But this type of race socialization not only has an impact on language. It also shapes the salience given to these racial labels, making them feel tangible and real-even for blind people who cannot directly perceive them (Krieger 1995; Zerubavel 1997).

Being able to identify society's differential treatment of racial minorities and recognizing that these social relations orient around visual differences is a key means through which the secondary distinctions that blind people can detect are transfigured into an unseen but nevertheless striking visual significance. Cognitively, it can therefore take on a visual significance for blind people that is no less significant than it is for sighted individuals (Zimler \& Keenan 1983). Michael, a blind respondent, provided an example of how this process works:

I began to be educated by people around me. For example, I might be talking to someone, and I would not necessarily know [their race] because I'm not looking at them. As far as I was concerned this was just a person, and someone would then come 
to me, and let me know that this person had been of a certain race, or color, or obvious ethnic origin which I would not have known. Sometimes [they would] impart information about their assumptions about that person, and how I should or should not behave, or who I should or should not be talking to.

These rules of engagement between different races - how to act, what to say, and what not to say-allow the visual distinctions between races to take on a fundamental role in how to treat various people according to how they are visually perceived even if the person cannot see them. This process is inextricably intertwined with notions of status, which are similarly communicated to blind individuals through visual understandings of race. As this section discusses some of the social interactions that give salience to visual understandings of race to blind people, it is imperative to keep in mind that socializing race's visual significance is an ongoing process that requires maintenance and reinforcement in order to elicit a continued "buy-in" from blind people.

Even where race is not explicitly discussed, difference is being asserted in a context where the importance of visual distinctions has already been established and is used to filter social experiences with racial content. The actual "work" of race socialization does not simply happen through dramatic experiences, but through everyday social interactions that largely go unnoticed yet accumulate over time to shape racial common sense - what becomes understood as a normal and expected part of the social world (Haney López 2004). For example, Jeremy remembered "being told by adults in [his] neighborhood that black people in the projects defecated on the floors and put it under their beds." Another blind white respondent, Mickey, provided an interesting sketch of how his father drew upon his other senses to instill a race sensibility that drew sharp contrasts between whites and blacks:

I was brought up to learn that I was white of course. And unfortunately I learned that I was white so that white could be contrasted with black. One of the first memories I have of learning about race was driving with my father downtown. And he said, "Do you smell that smell?" and indeed there was a smell. And I said yes. And he said, "That's the smell of nigger town." And I didn't know what that meant. But he was perfectly glad to tell me. That is where the Negro lived. And then he began to describe all the stereotypes with being a nigger or Negro ... [such as] "you know what you smell is partly the way that they keep their houses and their yards and there's just trash laying all around. But then part of what you smell is just them. They can't help it." And then he would go on: "Well, they talk differently because they're less educated and they're less educated because they're less capable of being educated." So pretty soon you begin 
to develop a race identity that kind of says wow, this is sad for them and sad for us too.

This respondent's father went out of his way to compensate for his child's physical inability to see race differences by drawing upon other senses - the smell of trash and poverty in urban environments, differences in speech patterns, etc. - to paint a picture that obscures the discriminatory social forces leading many blacks to inhabit impoverished social conditions. These outcomes were cast as a function of blacks' inherent racial tendencies - tendencies and differences that are typically most discernible through visual cues. One other blind white respondent, Timothy, had a similar experience, where anytime his family would travel from their suburban home into the main city,

they'd say "Well, we're entering nigger heaven." And I thought, "What is nigger heaven?" That was something that just [didn't immediately register].... What is a nigger? Why are you calling [them] niggers? Why? What's the deal? I thought, OK [black people] talked a little different. [But] I just don't understand this.

It is through these types of repeated social interactions that visual differences that cannot be immediately perceived can nonetheless become fantastically and vividly real. Socialization along other lines of perceptible difference can make imperceptible ones (such as those based on visual cues) seem like common sense. A belief system that race is visually obvious is being structured; its underlying architecture is the aspect of race that is hidden from yet nonetheless binds the sighted community as well, where race is simplistically experienced as it is seen. The experiences relayed by these blind respondents are not unique to the blind community. Rather, they reveal how all individuals are trained to seek and give meaning to the visual distinctions that society deems important. For example, Jan, a blind white respondent, described how she was socialized to "smell" differences between races:

We had this babysitter [Ellen], and I came down one morning and said [to my mother], "What are you doing?" She said, "I'm washing the counters," and I asked, "Why are you washing the counters?" She said, "Well, because black people smell, and your babysitter was here last night." And I said, "That's interesting," and filed that away. So, [Ellen] came the next week, and she was standing with her arm on the counter, and I walked up to the counter, and I sniffed it, and [Ellen] said, "What are you doing?" and I said, "Oh, I'm sniffing the counter, because my mom said you guys smell, and she's right. There's a smell that's different from ours on the counter."

This example illustrates how difference did not make a difference until the difference was pointed out and racialized, becoming a 
seemingly intrinsic part of who black people are as a group in the young mind of this respondent and feeding into the socialization process that the visual significance of race (which remains primary) is perceptible through other means. It would be erroneous to limit this experience to the young, impressionable mind of a child; recall Carl's ostensible ability to smell even the slightest hint of racial difference as an adult. These efforts to construct a race consciousness where differences are striking and pervasive suggests that it does not take a fantastic leap of logic for these social practices to inculcate a visual sense of racial difference among blind people and make visual cues seem like obvious boundaries among sighted individuals.

\section{Effects on Social Interaction}

It is tempting to suggest that blind people's visual understanding of race is superficial. Some may think that blind people are only repeating the visual characteristics that sighted people describe. From this perspective, blind people are merely "parroting" the way race is understood and experienced in the sighted community; they repeat what they hear about race without it having any real salience or substantially affecting their relations with others.

The data from this research demonstrate that this parrot thesis is not only inaccurate but may also be seen as offensive to many in the blind community. Many aspects of this research highlight how the visual significance blind people attribute to race has a profound and visceral impact on their daily lives in a manner that significantly undercuts the superficiality implied by the parrot thesis. One blind respondent provided an example of the remarkable effect this socialization can have:

My first memory of race is when I was a little girl and probably about 6 years old and I had a little [blind] friend and she was a black girl. She used to come home and visit. And at the time my mom used to conserve water, time, and energy by bathing kids together. She told [me and my black friend] to go upstairs and take a bath together, which is typically what she would do with me and my sister. And [my black friend] started to cry. She said that she couldn't do that.

Mom asked her why she couldn't do it and why she was so upset. But [she] just started to cry. I mean she became very, very distraught. My mom asked what the problem was, why she couldn't do it and why she was upset. And she said that if she did her black would rub off on me. And that was such a weird thing. I mean I didn't understand what in the world she was talking about. Because up until that point I didn't realize that [she] was any different than me. I thought [she] was just another blind kid in school, and we were all alike. At that time I didn't realize or didn't know that there was such a thing as black, white, or different people. 
I thought people were people were people. ... I had no idea how real [race] really was (emphasis added).

The blind black girl's houseparents were white and used this notion that blackness would "rub off" on white people as a socialization tool to keep her from intimate situations with white children - such as bathing with them-in order to enforce boundaries. This demonstrates the extent to which race is solidified as a material or "real" entity to create a belief system among blind and sighted alike that race is an observable and substantive trait.

Daniel, a blind black man, bluntly described the effects of being socialized into thinking about race visually as "perception is everything. How something is perceived, or how one class of folks are perceived is everything." Put differently, to be part of a culture that thinks visually about race and to be subject to social practices by friends, family, and institutions that fill these labels with substantive content is to affect the perception of the racial world, which in turn becomes reality. Just because blind people cannot see the racial dividing lines that people often organize their lives around does not mean that they are not compelled to organize their own lives similarly.

The interview data highlight numerous examples of how blind individuals' lives, decisions, and relationships revolve around visual understandings of racial difference - a finding remarkably similar to sighted individuals' experiences. Probably the most striking area to observe this phenomenon was in dating. Daniel, a blind black respondent, talked about the difficulties he had with dating outside of his race:

I just love African American women. I don't know why. I had white friends that I hung out with, and we went to class together, and worked on projects together. I just never had a desire to do that. ... I tried it, but I just couldn't gravitate to it. I think I did it for about a week, and I was just like, "No, I can't do this."

He went on to talk about some of the cultural dissimilarities that made dating outside of his race difficult, such as different tastes in music. Cultural barriers can certainly be difficult for people to transcend when dating interracially (Nash 1997), but this interview revealed an unvoiced difficulty with the race issue as it played out in terms of observable physical differences, not merely cultural ones. Other blind respondents voiced this hesitation as a desire to not disrupt social norms, knowing that interracial dating provides a visual image that they may not be able to perceive but is nonetheless looked down upon by others. For example, Dennis recalled a blind white friend's experience:

He was going to college and he had started working with a reader. She was very attractive to him, and he started seeing her. Then, 
somebody told him that she was black, and he broke it off. He broke off the relationship. He justified it by saying that it would not have worked, in the South, for a white man to be involved with a black woman.

Keith, a blind black man, discussed how race can become a primary filter in dating:

A lot of my black blind friends have sort of a joke because when someone doesn't know our race - especially the males - they'll find some way to reach out and touch our hair. People want to know, and that's the one [racial clue] they can always get.... People always come up with some kind of way to [touch our heads]. They'll massage you or do something. You know mostly you don't get too mad at blind people because a lot of them are touchy feely or whatever. And so you don't think anything about it. The next thing [you know] they went for your hair. It's a way for them to figure out [your race] if they don't know... .

I think [this happens] mostly in dating. You know, if they're going to make some decisions. I've seen people that seem sort of interested in someone and then discover that they're black and change their intentions. I go to a lot of the conventions now, the national conventions [for the blind]. And there are people trying to meet somebody [to date]. You can see that they're kind of pursuing somebody [that they find attractive]. And they'll go for the hair and then they'll change their mind. They're always still friendly. I've never known anybody who just stopped talking to anybody altogether. They'll give themselves some time. But you're black.

What stands out from this passage is how race is not simply a passive or descriptive characteristic that blind people happen to find out and store away in their minds as they meet people. Rather, it is information that is often actively sought to determine the nature and terms of any ongoing interaction. Tamara, a blind white respondent, said that knowing someone's race is useful because "it makes it easier to interact with them [so] I won't say a stupid thing ... something like a statement that would be assuming that they're white. [It's also important] just so that I can have equal access to information. I can say it matches the information that the sighted person has. It's really important to me."

Similar to their sighted counterparts, blind respondents' visual understanding of race lends itself to treating race as common sense - as an objective part of the social world that needs very little explaining. It just is. This understanding is not simply something that blind people keep to themselves. Rather, it shapes how they interact with others. The racial identity one builds through understanding one's physical appearance and group affiliation can be a significant if not wholly irrational barrier. The norms that people 
are socialized into affect how they view themselves and others for the rest of their lives. Gina, who is blind and white, recalled a time as a child where she was at the beach,
And my dad was on a rock... and he was fishing .... We were down in the water some little bit of distance from him. And a boy came. And we were talking with him. He sounded like he was my age. We were just fooling around and having fun in the water. Turns out this was a black boy. I did not know that. But my dad looked down and saw us and became so upset and agitated that he slipped coming down the rock. And [he] had a bottle of cough syrup in his pocket because he developed a cough. And it broke. And he cut his hip really badly because he was so upset that I was in the water talking to this black boy.

Experiences such as these where the visual boundaries of race and social relations are patrolled and maintained to create a profound sense of difference between groups can have a lasting effect on how individuals relate to even ancillary aspects of racial difference. Gina went on to describe these effects through an experience several decades later, when she went to an estate sale for a recently deceased black woman:

And so it turns out that the dead woman was my same size. And so I purchased a few of her dresses and things. And when I put them on, I felt really strange knowing that she was a black person. And I really ... I don't know where that feeling came from. And searching my soul about it, I think it was baggage from the way I was raised and how I had been indoctrinated as a child and a young person. And I think that just bubbled up and I had to say $\mathrm{OK}$, is this really me? Is this what I really think? ... I was ashamed of that feeling.

The irrationality of this response is inextricably intertwined with how a visual understanding of difference shaped by social interactions (such as her father forbidding black playmates) affected how she as a white woman felt wearing something once owned by a black person. The knowledge that the deceased lady was black and belief that this difference mattered led to feelings of anxiety and shame. Whether or not Gina could see this difference associated with these distinctions mattered very little.

This section has gone beyond demonstrating blind people's visual understanding of race to show how the constitutive social practices that give rise to it also have a significant impact on blind people's social interactions and daily lives. In short, the visual significance of race is produced rather than merely observed. These constitutive social practices reveal themselves through an examination of blind people's experiences but nonetheless shape the racial consciousness of blind and sighted alike. These data provide an 
empirical standpoint from which to rethink the widespread presumption that the visual salience that people attribute to race is unmediated, obvious, and self-evident. Put bluntly, race has less to do with what one sees than how one is socialized to see, regardless of whether one can see or not.

\section{Conclusion: Rethinking Race in Law, Society, and Beyond}

The data from these interviews raise new questions about how race becomes visually salient and the role of vision in individuals' racial consciousness. The findings - that social practices give rise to visual understandings of race rather than racial boundaries simply being self-evident or obvious - are a contribution that is related to yet distinct from previous scholars' demonstration of the social construction of race. For example, the first generation of Critical Race Theory's social construction scholarship has productively focused on historical evidence, doctrinal critiques, and postmodern theory - a macro-level contribution to understanding how broad social forces (not nature or human evolution) give meaning to race in a manner that sustains racial hierarchy (Allen 1994, 1997; Bell 1993; Williams 1987). But what has until now remained relatively unexamined is an account, beyond mere intuitions and assumptions, that investigates how the visual cues that mark racial boundaries stand out as salient in the first place-in other words, to pierce the assumption that race reflects obvious and self-evident boundaries of human difference. This article does this through a second-generation contribution to Critical Race scholarship that moves from macro to micro - from historical accounts, legal doctrine, and theory to an empirical analysis - to offer qualitative data that flesh out the particular types of social interactions that constitute the visual significance given to race. This article shows this by examining how visual cues come to matter for blind people and, therefore, the ways in which social practices give rise to visual understandings of race for all individuals. This constitutive theory of race, which emphasizes the social interactions that make specific human divisions thinkable and perceptible, is distinct from firstgeneration efforts in Critical Race Theory that highlight the social, economic, and political factors leading certain meanings to attach to various bodies (Banks 1999; Jones 1999).

While recent scholarship has demonstrated the extent to which racial perception and identity are not fixed but shift across time, social contexts, and experiences (Penner \& Saperstein 2008; Telles 2002) this article demonstrates the extent to which the visual cues thought to be salient boundaries of and reference points for racial knowledge are produced from the inside out rather than the 
outside in. That is, racial knowledge does not simply emanate along the constructionist dimension whereby broad forces such as law, economics, politics, and other social institutions create the largescale rules for which meanings attach to specific bodies. Rather, iterative social practices informed by but not reduced to these broader social norms constitute another dimension of racial knowledge that makes it possible for individuals to "see" the very racial boundaries that come to be experienced as self-evident examples of human difference. With the constructionist account, the visual obviousness of race is the starting point for scholarly critique rather than, as it is in the constitutive approach, a subject for critiquing.

By empirically demonstrating the social processes that give rise to visual understandings of race, these findings suggest that the visual salience with which people experience race operates in the absence of any requirement to actually see the visual cues that come to define racial boundaries. These perceived visual distinctions are constituted by social practices that are so strong that even blind people, in a conceptual sense, "see" race and organize their lives around visual understandings of racial difference. Paradoxically, vision blinds the sighted community from appreciating these practices' significance. Blind people's experience of not being able to see the visual cues associated with race brings these practices to the forefront, providing entrée into understanding the extent to which these practices affect the way all people understand race.

These findings can have significant implications for race theory. Without a doubt, racial formation and the social construction of race are interactive processes between what one sees in the world and the categories created by social convention. Yet the overreliance on vision as unmediated racial truth may also limit deeper understandings of how, for example, law and society produce the ability to see the very racial differences throught to be obvious and self-evident. Put differently, it is one thing to say that race is a social construction in that its stratified meaning system is not supported by inherent, natural, or biological differences. It is quite another to demonstrate empirically that (1) the conventional body markings used to differentiate races are not simply visually obvious boundaries whose perceptibility is anterior to social forces and (2) that the visual significance and salience of race is not diminished for those without vision. A clearer delineation between firstgeneration critiques of race reflecting inherent, natural, or biological differences from this proposed second-generation critique of race reflecting self-evident visual differences may offer insight into how to best think about the constitutive social practices that produce visual understandings of race - as both distinct from and a continuation of the construction of racial meanings and their attachment to various bodies. 
What might these findings and, in particular, this new constitutive theory of race mean for the role of race in law and society? One way to think about the theoretical implications is through the emerging color blindness discourse. Color blindness can be understood as a perspective that the state should be "blind" to color; all race-conscious government action should be considered equally suspect, regardless of whether the stated goal is harmful, helpful, or benign (Brown et al. 2003; Bonilla-Silva 2006). This approach is having a growing influence on how legislatures and the judiciary think about law and racial justice. For example, Supreme Court Chief Justice John Roberts recently noted in a school desegregation case that "the way to stop discrimination on the basis of race is to stop discriminating on the basis of race," which legally and morally equates race-conscious efforts to desegregate schools with race-conscious efforts to segregate them (Parents Involved in Community Schools v. Seattle School District, 551 U.S. 701, 748 2007).

It would be a mistake to take the color-blind metaphor literally; no one seriously thinks that it is possible to stop noticing an individual's skin color or other attributes. Yet metaphors matter, in terms of making certain ideas about the world thinkable and coherent (Lakoff \& Johnson 1999, 2003). The color-blind metaphor reflects and produces a particular theory of race that has increasing legal and policy influence and is addressed by this article's empirical critique: that race is visually obvious and that its social import stems almost wholly from visual distinctions. Indeed, this implicit theory of race provides the normative prima facie claim conveyed by the color blindness metaphor: Laws that are "blind" to "color" lead to a more equitable and fair society. Color blindness and its underlying theory of race strongly imply that race and racism are problems of visual recognition and not social or political practices. Put differently, all that law and society have toand ought to-do is stop paying attention to race, treat people as deracialized individuals, and justice will follow. The empirical findings in this article complicate color-blind theory (beyond existing scholarly demonstrations of its limitations) by demonstrating that the perceptibility and visual salience of race are social rather than merely ocular phenomena, which disrupts the coherency of the color-blind metaphor and thus its jurisprudence. This disruption highlights a critical point: If scholars, legal actors, and policy makers do not understand the extent to which seeing race-a process anterior to yet connected with meaning attaching to certain types of bodies - is a micro-social phenomenon rather than a self-evident trait that people possess and society merely observes, then we may be less inclined to interfere in this process in a manner that encourages social change. Any commitment to racial justice needs a 
deeper engagement with race as a social and cultural issue rather than relying upon a jurisprudence of racial nonrecognition.

At the same time, this research may also have important implications for legal doctrine, specifically in terms of how we think about Fourteenth Amendment equal protection jurisprudence. The Court has developed varying levels of judicial scrutiny as a mechanism to provide greater oversight to protect vulnerable groups from state-sponsored classifications that are discriminatory. The Court takes three factors into consideration when deciding whether to apply strict scrutiny, intermediate scrutiny, or mere rational review: (1) whether the plaintiff is a member of a politically powerless group, (2) whether the plaintiff is a member of a group that has experienced a history of discrimination, and (3) whether the plaintiff is part of a group that is distinguished by an "obvious, immutable, or distinguishing characteristic" (Bowen v. Gilliard 1987:602). The third prong provides the most direct articulation of what Yoshino calls equal protection's visibility presumption, where the visibility and immutability of a group's shared characteristic plays a gatekeeping function in determining which groups receive more judicial protection, with race being the model (Yoshino 1999). Yoshino argues that granting greater scrutiny to those groups whose state-enforced categorizations are premised upon visible body differences creates a legal bias against groups that experience discrimination based on characteristics that are not tightly connected to visual cues (such as homosexuality).

According to Yoshino, this visibility presumption leads courts to misunderstand how discrimination operates outside of vision. But the empirical evidence from this research might give Yoshino's critique of equal protection's limitations greater specificity. The visibility presumption may not only prematurely exclude deserving groups from judicial protection, but it may also inadvertently assist racial subordination by focusing equal protection inquiries on what people look like rather than the social practices that make such visual distinctions salient and perceptible. Thus, this research into blind people's racial experiences may sociologically ground the problems associated with equal protection jurisprudence isolating race as a visual experience while also demonstrating how this visibility presumption is intertwined with maintaining systems of racial dominance.

When the assumptions and intuitions that shape legal theory, policy preferences, or judicial review are not empirically accurate, there is a significant disjunction or mismatch between the way law understands how society operates and the way it actually does. This can lead to injustice, particularly for vulnerable communities. Without seriously considering how social practices constitute visual understandings of race, law's emphasis on visual cues can obscure 
the extent to which people are socialized to think racially, which may very well be at the heart of many discriminatory actions that may go without a remedy due to the current emphasis on what plaintiffs look like.

Taken together, this research helps demonstrate this disjunction between the visibility presumption in law and society and the constitutive nature of visual understandings of race. Further research that embraces both constructionist and constitutive approaches to race-being savvy with regard to the history and theory of racial meaning while also being empirically rigorous with regard to how such differences become thinkable - can encourage more sophistication in race conversations. Moreover, it can provide a path for greater empirical scrutiny of legal framings to ensure the accuracy of law's understanding of race relations.

\section{References}

Ahmed, Patricia, et al. (2007) "Internal and External Ethnic Assessments in Eastern Europe," 86 Social Forces 231-54.

Allen, Theodore W. (1994) The Invention of the White Race: Racial Oppression and Social Control. London: Verso.

- (1997) The Invention of the White Race: The Origin of Racial Oppression in Anglo-America. London: Verso.

Banks, Taunya L. (1999) "Colorism: A Darker Shade of Pale," 47 UCLA Law Rev. 1705-46.

Bell, Derrick (1993) Faces at the Bottom of the Well: The Permanence of Racism. New York: Basic Books.

Berger, Martin A. (2005) Sight Unseen: Whiteness and American Visual Culture. Berkeley: Univ. of California Press.

Bonilla-Silva, Eduardo (2006) Racism Without Racist: Color Blind Racism and the Persistence of Racial Inequality in the United States. New York: Rowman and Littlefield.

Bothwell, Robert K., et al. (1989) "Cross Racial Identification," 15 Personality and Social Psychology 19-25.

Braman, Donald (1998) "On Race and Immutability," 46 UCLA Law Rev. 375-1463.

Brown, Michael, et al. (2003) Whitewashing Race: The Myth of a Color-Blind Society. Berkeley: Univ. of California Press.

Caldwell, Paulette (1991) "A Hair Piece: Perspectives on the Intersection of Race and Gender," 1991 Duke Law J. 365-96.

Connolly, Andrew C., et al. (2007) "Effect of Congenital Blindness on the Semantic Representation of Some Everyday Concepts," 104 Proceedings of the National Academy of Sciences 8241-6.

Crary, Jonathan (1994) Techniques of the Observer: On Vision and Modernity in the Nineteenth Century. Cambridge, MA: MIT Press.

(1999) Suspensions of Perception: Attention, Spectacle, and Modern Culture. Cambridge, MA: MIT Press.

Crenshaw, Kimberle (1991) "Mapping the Margins: Intersectionality, Identity Politics and Violence Against Women of Color," 43 Stanford Law Rev. 1241-99. 
Crenshaw, Kimberle, et al. (1995) "Introduction," in K. Crenshaw et al., eds., Critical Race Theory: The Key Writings that Formed the Movement. New York: The New Press.

Davis, Darren W. (1997) "The Direction of Race of Interviewer Effects Among African Americans: Donning the Black Mask," 41 American J. of Political Science 309-22.

Eberhardt, Jennifer L., et al. (2004) "Seeing Black: Race, Crime, and Visual Processing," $87 \mathrm{~J}$. of Personality and Social Psychology 876-93.

Faugier, Jean (1997) "Sampling Hard to Reach Populations," 26 J. of Advanced Nursing $790-7$.

Flagg, Barbara J. (1993) “"Was Blind, But Now I See': White Race Consciousness and the Requirement of Discriminatory Intent," 91 Michigan. Law Rev. 953-1017.

Geyer-Ryan, Helga (1996) "Imaginary Identity: Space, Gender, Nation," in M. Jay \& T. Brennan, eds., Vision in Context: Historical and Contemporary Perspectives on Sight. New York: Routledge.

Gómez, Laura (2004) "A Tale of Two Genres: On the Real and Ideal Link Between Law and Society and Critical Race Theory," in A. Sarat, ed., Blackwell Companion to Law and Society. Malden, MA: Wiley.

Gould, Stephen J. (1996) Mismeasure of Man. New York: Norton.

Gossett, Thomas (1997) Race: The History of an Idea in America. London: Oxford Univ. Press.

Gray, David E. (2004) Doing Research in the Real World. London: Sage.

Groves, Robert M., et al. (2004) Survey Methodology. Hoboken, NJ: Wiley.

Hammersley, Martyn, \& Roger Gomm (1997) "Bias in Social Research," Sociological Research Online, http://www.socresonline.org.uk/2/1/2.html (accessed 24 June 2009).

Haney López, Ian (1994) "The Social Construction of Race: Some Observations on Illusion, Fabrication, and Choice," 29 Harvard Civil Rights-Civil Liberties Law Rev. $1-62$.

—_ (1996) White By Law: The Legal Construction of Race. New York: New York Univ. Press.

- (2004) Racism on Trial: The Chicano Fight for Justice. Cambridge, MA: Belknap.

Harris, Angela P. (1990) "Race and Essentialism in Feminist Legal Theory," 42 Stanford Law Rev. 581-616.

Harris, Cheryl (1992) "Whiteness as Property," 106 Harvard Law Rev. 1707-91.

Hirschfeld, Lawrence (1996) Race in the Making: Cognition, Culture, and the Child's Construction of Human Kinds. Cambridge, MA: MIT Press.

Jay, Martin, \& Teresa Brennan (1996) Vision in Context: Historical and Contemporary Perspectives on Sight. New York: Routledge.

Johnston, Patricia (2006) Seeing High and Low: Representing Social Conflict in American Visual Culture. Berkeley: Univ. of California Press.

Jones, Trina (1999) "Shades of Brown: The Law of Skin Color," 49 Duke Law J. 1487557.

Jordan, Winthrop (1968) White Over Black: American Attitudes Toward the Negro, 15501812. Chapel Hill: Univ. of North Carolina Press.

Kang, Jerry (2005) "Trojan Horses of Race," 118 Harvard Law Rev. 1489-593.

Krieger, Linda (1995) "The Content of Our Categories: A Cognitive Bias Approach to Discrimination and Equal Employment Opportunity," 47 Stanford Law Rev. 1161-248.

Kwon, Peter (1997) "Jeffrey Dahmer and the Cosynthesis of Categories," 48 Hastings Law J. 1257-92.

Lakoff, George, \& Mark Johnson (1999) Philosophy in the Flesh: The Embodied Mind and Its Challenge to Western Thought. New York: Basic Books. - (2003) Metaphors We Live By. Chicago: Univ. of Chicago Press.

Lippi-Green, Rosina (1997) English With an Accent: Language, Ideology, and Discrimination in the United States. London: Routledge Press. 
Loveman, Mara, \& Jeronimo O. Muniz (2007) "How Puerto Rico Became White: Boundary Dynamics and Intercensus Racial Reclassification," 72 American Sociological Rev. 915-39.

Madeline, Milian, \& Jane N. Erin, eds. (2001) Diversity and Visual Impairment: The Influence of Race, Gender, Religion, and Ethnicity on the Individual. New York: AFB Press.

Marmor, Gloria Strauss (1978) "Age of Blindness and the Development of the Semantics of Color Names," $25 \mathrm{~J}$. of Experimental Child Psychology 267-78.

Martin, John Levi, \& King-To Yeung (2003) "The Use of the Conceptual Category of Race in American Sociology," 18 Sociological Forum 521-43.

McCann, Michael (1996) "Causal versus Constitutive Explanations (or, On the Difficulty of Being So Positive ...)," 21 Law and Social Inquiry 457-82.

Meissner, Christian A., \& John C. Brigham (2001) "Thirty Years of Investigating the Own-Race Bias in Memory for Faces: A Meta-Analytic Review," 7 Psychology, Public Policy, and Law 3-35.

Nash, Renea D. (1997) Coping With Interracial Dating. New York: Rosen Publishing Group.

Niemonen, Jack (1997) "The Race Relations Problematic in American Sociology," 28 American Sociologist 15-54.

Obasogie, Osagie (2006a) "Race in Law and Society: A Critique," in I. Haney López, ed., Race, Law, and Society. Surrey, UK: Ashgate Publishing.

—_ (2006b) "Anything But a Hypocrite: Interactional Musings on Race, Colorblindness, and the Redemption of Strom Thurmond," 18 Yale J. of Law E Feminism 451-95.

Omi, Michael, \& Howard Winant (1994) Racial Formation in the United States: From the 1960 s to the 1990s. New York: Routledge.

Penner, Andrew, \& Aliya Saperstein (2008) "How Social Status Shapes Race," 105 Proceedings of the National Academy of Sciences 19628-30.

Pinder, Kymberly N. (2002) Race-ing Art History: Critical Readings in Race and Art History. New York: Routledge.

Richardon, Stephen, et al. (1965) Interviewing: Its Forms and Functions. New York: Basic Books.

Rose, Jacqueline (1986) Sexuality in the Field of Vision. London: Verso.

Sampson, Edward E. (1999) Dealing With Differences: An Introduction to the Social Psychology of Prejudice. Fort Worth, TX: Harcourt Brace.

Siegel, Reva (2000) "Discrimination in the Eyes of the Law: How Colorblindness Discourse Disrupts and Rationalizes Social Stratification," 88 California Law Rev. 77-118.

Stienstra, Deborah (2002) "The Intersection of Disability and Race/Ethnicity/Official Language/Religion." Unpublished paper, Canadian Centre on Disability Studies, University of Winnipeg, 8 March.

Telles, Edward E. (2002) "Racial Ambiguity Among the Brazilian Population," 25 Ethnic and Racial Studies 415-41.

Waters, Mary (1990) Ethnic Options: Choosing Identities in America. Berkeley: Univ. of California Press.

Weiss, Robert S. (1994) Learning From Strangers: The Art and Method of Qualitative Interview Studies. New York: Free Press.

Williams, Patricia J. (1987) "Alchemical Notes: Reconstructing Ideals from Deconstructed Rights," 22 Harvard Civil Rights-Civil Liberties Rev. 401-34.

Wing, Adrienne Katherine (1997) "Essentialism and Anti-Essentialism: Ain't I a Woman?," in A. K. Wing, ed., Critical Race Feminism: A Reader. New York: New York Univ. Press.

Yoshino, Kenji (1999) "Assimilationist Bias in Equal Protection: The Visibility Presumption and the Case of 'Don't Ask, Don't Tell,", 108 Yale Law J. 485-571. 
Zerubavel, Eviatar (1997) Social Mindscapes: An Invitation to Cognitive Sociology. Cambridge, MA: Harvard Univ. Press.

Zimler, Jerome, \& Janice Keenan (1983) "Imagery in the Congenitally Blind: How Visual Are Visual Images?," $9 \mathrm{~J}$. of Experimental Psychology 269-82.

\section{Cases Cited}

Bowen v. Gilliard, 483 U.S. 587, 602 (1987).

Parents Involved in Community Schools v. Seattle School District No. 1, 551 U.S. 701 (2007).

Osagie K. Obasogie is an Associate Professor of Law at the University of California, Hastings College of Law with a joint appointment at the University of California, San Francisco (UCSF), Department of Social and Behavioral Sciences. His research focuses on bridging the conceptual and methodological gulfs between social science research and legal scholarship on race to offer new insights into the relationship between race, law, and society. 